\title{
The Effects of a Brand's Online Presence on Brand Awareness and Brand Loyalty: A Study of UAE Millennials
}

\author{
Muhamad Sham Shahkat Ali \& Menatullah Nasr \\ College of Arts and Sciences, Abu Dhabi University, United Arab Emirates
}

\begin{abstract}
Digital marketing has become an important facet of any organization's overall marketing plan, and it could be argued that a brand's presence on the internet has become as equally important as its physical presence in the real world. This study highlights the importance of a brand's online presence and its effect on brand awareness and brand loyalty in the light of the two-way symmetrical communication model and the uses and gratification theory. The study was conducted in the UAE, and therefore the UAE market was the primary focus of the study. The study also focuses on millennials, as they have been found to be the age group with the heaviest internet and social media use. 6 aspects of a brand's online presence were outlined and examined for this study, and they are: (1) a brand's appearance in search engine results (2) a brand's website (3) a brand's social media activities (4) online advertising (5) brands' mobile application and (6) a brand's e-mail correspondence. Focus group were conducted with 20 male and female millennials living in the UAE in order to seek their insights on the topic of the study.
\end{abstract}

Keywords: Branding, Brand Loyalty

\section{INTRODUCTION}

Social Media Marketing has become a phenomenon in its own right, and it's one that affects brands and customers equally. It has become agreed upon that a brand's presence on the internet is as vital to its survival as its physical presence in the real world (Green, 2013). A study of Korean luxury fashion brands found social media marketing to have a strong impact on brand equity and the customers' intent to purchase. It emphasized that a brand's online presence and its continuous engagement with its customers add certain value to a brand's image that traditional media and marketing could not provide (Kim \& Ko, 2012).

This study seeks to build on this assumption by examining the effects of all aspects of a brand's online presence on customer retention and loyalty in general with specific focus on the market of the United Arab Emirates. Previous research has revealed that millennials (those whose ages are between 18 and 32) are the heaviest among all generations in their reliance and embracing of social media, and the most likely to use social media and the internet to find out more about brands and products (Frady, 2011) (Close-Up Media Inc., 2014); which makes millennials the ideal population for this study. Therefore, the purpose of this research is to examine the effects of a brand's online presence on brand awareness and customer loyalty amongst UAE millennials, and to highlight what constitutes a positive online presence for any brand.

\section{LITERATURE REVIEW}

For consumers to start any form of contact with a brand, they first have to know about the brand's existence. This is what is known as brand awareness. Basically, brand awareness is achieved when a customer is able to recognize a certain brand on sight and recall it at will. It can range from vaguely recognizing a brand's name or logo as familiar, for example, to knowing a brand and its products well and associating certain perceptions and ideas with that brand (Aaker, 2009). A study of Linen Me, a Danish brand, found that the internet can be a very effective tool in increasing brand awareness, and that brands that utilize the online tools effectively can easily achieve that (Galvez, 2014). A study on the effects of social media on brand awareness that focused on examining the Facebook page of international car brand MINI further emphasizes the previous claim. The study found that social media engagement of a brand has a clear positive impact on brand awareness, and can generate affirmative word-of-mouth about the brand (Hutter, Hautz, Dennhardt, \& Füller, 2013). A study conducted in Malaysia found that elements of a brand's social media presence, such as a brand's 
Facebook page, to play a crucial role in creating brand awareness among Malaysian consumers (Haque, Momen, Sultana, \& Yasmin, 2013).

After a consumer has been in contact with a brand, he or she begins to form perceptions and attitudes and even emotions towards the brand. If the consumer starts a purchasing relationship with a certain brand, he/she becomes one of its customers. With repeated purchase, the customer develops what is known as customer loyalty towards a brand. Customer loyalty or brand loyalty is a customer's commitment or attachment to a brand that drives him/her to continuously purchase the product or service of the said brand. Hence, it can be said that the customer is "loyal" towards that brand. Customer loyalty is often seen as one of the major profit drivers for any business, and "keeping the customer" is always a priority (Alrubaiee \& Al-Nazer, 2010). Customer loyalty has been found to be connected to customer satisfaction; i.e. if a customer is satisfied with a brand's performance and product/service, he/she is more likely to become loyal to that brand (Maharaj, 2008). A recent study of Facebook users has found that when brands engage their customers in online community, their customer loyalty increases. This emphasizes the importance of online communication between brand and customer in order to maintain that loyalty (Zheng, Cheung, Lee, \& Liang, 2015). Another study with similar focus on brand Facebook pages found that customer engagement through social networks like Facebook affects customer loyalty to brands and can play a major role in generating positive or negative word of mouth about a brand. The better the image a brand gives off, the better a customer's perception of a brand, the more likely they are to engage in communication with the brand; and therefore, there more likely they are to form an attachment to that brand and be part of its online community (De Vries \& Carlson, 2014).

The main scope through which this paper looks at online brand communication is the two-way symmetrical communication model by James E. Grunig. The model sees communication as a twoway process in which an exchange of information is shared from both parties involved in any communication. This is in contrast with older communication models used in traditional advertising, in which one party send out its own crafted messages and the other merely plays the role of the receiving, taking in and processing the said messages without any ability to respond (Lattimore, Baskin, Heiman, \& Toth, 2011). By this, the researcher does not claim that all existing online communication is an example of two-way symmetrical communication in its nature, but ideally this is how it should be. That is, if a brand seeks to establish a strong, it should follow this communication model. Hence, this research is a buildup on this assumption where Grunig's two-way symmetrical communication is the model followed in executing all of a brand's online communication.

Additionally, the uses and gratification (UG) theory is the other theory used in this research. UG views people as active media users, not simply passive receivers who embrace all forms of media they encounter. According to this theory, people choose the media they pay attention to, how to utilize these media, and have reasons for selecting said media. People also choose to interpret media messages in their own ways, and thus not everyone will have the same idea about media messages that brands send out. Researchers found 4 reasons that people use media, and those are:

- "As entertainment"

- "To scan the environment for items important to them personally"

- "As a diversion"

- "As a substitute for personal relationships"

- "As a check on personal identity and values"

(Lattimore, Baskin, Heiman, \& Toth, 2011).

When applied to the virtual world, this means that internet users choose what brands to engage with and through what mediums. A user will not simply click an ad, go through a brands website, or follow a brand's page unless he/she has enough reason to do so. Brands have to know how to approach the online consumer, how to get their attention, and how to keep that attention in order to properly engage them. Based on the previous information, brands need to make their web content entertaining and to make know how to promote it in such a way that makes the user feel like it holds personal value or benefit to them. 


\section{Evidence from the UAE}

Not many studies have been conducted about the effect of brands' online communication with specific focus on the UAE. However, some previous researches exist that give us insight into relevant topics. As far as over a decade ago, in 2003, a study was conducted that saw e-commerce as a growing sector in the UAE. It predicted that if consumer awareness of how the internet works (given that the level of awareness on internet issues at the time the study was conducted was fairly low) grows among the UAE population, e-commerce will flourish and could become an effective marketing tool (Darby, Jones, \& Al-Madani, 2003). Has the status of internet use changed in UAE since then? A 2011 study on the use of social media in the UAE in general revealed the importance of social media to young people in the UAE. Social media was cited as a trusted source for news and information by participants in a survey conducted by the researcher. The participants, all residents of the UAE, showed high awareness of the different social media outlets that exist in the virtual world. Additionally, their preferred social networks were the same ones that are popular in the rest of the world, such as Facebook and YouTube (Al-Jenaibi, 2011). This awareness of social media and indicators of its frequent use by UAE residence shows the importance of social media to the UAE population today. And since the population seems heavily invested in social media use, it makes social media an important channel that people pay a lot of attention to, and should therefore be invested in as a vital marketing tool.

On the other hand, brands and businesses in the UAE were not as keen about using social media as the rest of the population, according to a 2013 study conducted for the University of Wollongong in Dubai. The qualitative study, focused on gathering data from previous research, shows that only $41 \%$ of all UAE businesses actually use social media. And of these businesses, none of them seemed to know how to properly utilize the medium for their benefit. Most social media use by brands in the UAE was too "overt" to actually engage customers. As in, most of the items posted by companies on social media were outright ads that were not inviting to customers, seeming more like a traditional form of advertising than anything. Additionally, most companies in the country (around 80\%) showed reluctance to use social media out of fear of making mistakes that could threaten their reputation. They were afraid of failing in generating positive online communication and not knowing how to deal with negative comments from customers (Koshy, 2013). Basically, we see that there is a disparity between customers and businesses in UAE when it comes to social media. While customers are advancing in their reliance on social media for different information gathering processes, brands are still dragging their feet, and are thus falling behind in engaging their customers through this medium that has become a focal point of everyday life. There needs to be more effort by brands to communicate with customers online, and to make their online presence visible in a confident, engaging manner.

A study about online banking found that UAE customers would be willing to embrace online banking technologies based on how easy-to-use and how useful these technologies are proven to be to them. The study claims that if bankers market these technologies in a way that makes customers perceive them as useful and efficient, the customers could start taking on these technologies and using them for day-to-day banking operations. The study also found that consumers in the UAE care more about how easy an online service is to use and how seemingly useful than about how safe or secure it is. The reason, as the study attributes, for this is that computer literacy is still relatively low amongst the UAE population than in Europe or USA, and thus they have lower risk perception than in those other regions (Mouakket, 2009). This study implies two main things: (1) the willingness of UAE customers to embrace online commercial technologies should the reasons be given to them, and (2) the low riskperception for UAE customers means it would be easier for them to trust online marketing technologies than it is for other customers around the world. This would be a comforting indication for any business that seeks to provide future e-services to customers that the customers wouldn't need too much reassurance when it comes to security risks. However, it is not equally comforting for the public to not have a high level of awareness about security risks that could come about from using online services.

Aside from previous research studies, the researcher has found several news articles from major news outlets in the UAE that contain useful implications for this study. In 2015, Gulf News published a report titled "UAE Consumers More Active that Global Average on Social Media". The article cites a 
report by BT \& Avaya. The report states that UAE consumers were found to be more "tech savvy" than any other consumers in the world, utilizing different communication platforms on the web to help them make their buying decisions. It adds that consumers in the UAE use online communication very heavily, and now expect brands to keep up with that pace. They want brands to become more interactive, providing customers with as many outlets as possible for communication and outreach. The article predicts that this could be an effective way for brands to encourage loyalty among customers, which emphasizes the notion established previously in this review that the more engaging a brand is, the better it utilizes technology, the more it can retain its customers (Gulf News Staff Report, 2015). Adding to this information, an Emirates 24/7 report, citing the Global Trust in Advertising Report by Nielsen, stated that $75 \%$ of UAE consumers trust online reviews about products, and $72 \%$ of them trust branded websites. Moreover, $57 \%$ of the UAE participants in Nielsen's study said they trusted online video ads, while 54\% and 59\% said they trusted search engine ads and social media ads respectively (Emirates 24/7 Staff, 2015).

A Khaleej Times report as recently as December $5^{\text {th }}, 2015$ saw the e-commerce sector in UAE growing drastically in the next few years. Citing a research by MasterCard, the report states that the total e-commerce value is expect to grow from its current value of 2.5 Billion USD in 2015 to 10 Billion USD in 2018. Additionally, it predicts that internet retail would grow by $95 \%$ in the UAE in the next 5 years. The ease of use and accessibility of internet portals makes it an attractive outlet for customers, and it is already gaining popularity in the present. This continuously growing interest from customers in online services provides a significant opportunity for businesses to invest in in order to attract the modern customer in a fast-paced world (Sabeeh, 2015). Another recent article from Khaleej Times claims that mobile apps have a higher market-penetration rate in the UAE than in any other country in the world. Apps that allow users to order different products online, such as Zomato, Souq, and MarkaVip, are greatly popular amongst UAE internet users, who are estimated to be $92 \%$ of the UAE population. The report attributes this popularity to the good development and ease of use of these apps (Shabeeh, 2015). All of this represent an opportunity for UAE businesses and proves that a brand's presence online has become as vital to doing business and gaining customers as any other aspect of its existence.

Two more reports, from Khaleej Times and The National, talk about entrepreneurship in the UAE, demonstrating the value of social media in popularizing small businesses in the UAE. The first article discusses the career of three young women in the GCC who, with the help of Instagram, were able to launch their own fashion brands, bringing their talent forward and helping them create relatively successful online businesses (Gokulan, 2015). Similarly, the second article, from The National, discusses the rise of two Instagram baking businesses operated by two ladies from the UAE. Hind Al Mullah, founder of Home Bakery, was able to elevate her business from a simple home project to opening her own, fully operational bakery with the help of Instagram alone (Dhaheri, 2015). If social media has the power to launch individual entrepreneurs to success on a national level, then it surely can be a valuable tool in simply furthering the popularity of any existing brand. As it was repeatedly emphasized, social media and the internet keeps presenting itself as an opportunity to be seized by businesses to gain new customers and keep their old customers engaged.

\section{Methodology}

For this paper, the researcher aimed to gain as much of customers' perspectives as is possible on the value of online brand presence to customers. Hence, the depth of the data was more critical to achieve the researches purposes than the quantity, and that is why the method chosen for this research was focus group with customers who fall into the research's selected demographic, millennials. Moreover, focus group were seen as the best way to get the most organic answers from participants, instead of only giving them limited choices from pre-set categories. This way, participants could express themselves without constraints and to give all possible insights they could have regarding the topic. 20 millennials were selected for this research, 10 of them being males and 10 females.

The same set of questions was asked to the male and female participants. The following is the list of questions used in the focus group.

1) How important do you think it is for a brand to be active on the internet? Why so?

2) Have you ever found out about a brand through a search engine? If so, explain.

3) Do you look up brands you just found out about online? If so, what do you expect to find when you google a brand's name? 
- Follow up question: what are your thoughts when you cannot find a brand's website or social media through internet searches?

4) How often do you check brand's websites? What should an ideal brands' website look like or what should it contain in your opinion?

5) Is it important, in your opinion, for a brand to be active on social media? Why or why not?

6) Do you follow any brands on social media? What type of brands do you follow and why do you follow them?

7) Has a brand's social media page ever enhanced your perception about that brand in a positive way? How so?

8) Did you ever end up having a negative perception of a brand because of its social media page? Explain.

9) Do you ever communicate with brands on social media (whether through tweets, Facebook, Instagram, snapchat, or any other social network...)? What kind of response do you expect from brands when you communicate with them on social media?

10) Do you pay attention to online advertising (banner ads on websites, pop-up ads, YouTube ads, or sponsored posts on Instagram or twitter)? Do you think this form of advertising is helpful?

11) Do you have any brand's mobile app downloaded to your phone? If so, which apps, how do you use them, and how often do you use them?

12) Do you think it's important for a brand to have a mobile app? Why or why not?

13) Have you ever tried communicating with any brand through e-mail? If so, how responsive were they?

14) Would a brand's e-mail correspondence affect your perception of the brand in any way? How so?

15) Ideally, what kind of e-mails do you think a brand should send to its customers?

The variety of these questions was meant for the purpose of addressing each of the six aspects of a brand's online presence that were determined for this research. As previously mentioned, these aspects are (in their order of appearance in the focus group interview questions):

1. A brand's appearance in search engine results: Addressed in questions 2, 3 and the follow up question, the purpose was first to find out if search engine results can generate brand awareness; i.e. if a customer can first be exposed to a brand through search engine results. In question 3, the researcher intended to know through insights how search engine results contribute to a consumer's continued engagement with a brand. At the stage where a consumer searches a brand name, he/she must already be aware of the brand's existence, and have certain interest in finding out more about a brand. Thus, a customer's expectations when searching for that brand and his/her impression if they cannot find a brand through a simple search are the key to understanding how search engine results can be a starting point of building up a relationship with a consumer.

2. A brand's portal or website: Question 4 was designed to acquire information about customers' expectations of brand websites, in order to determine what a brand should do to improve their online portals.

3. A brand's social media presence: as has been proven by previous research, social media activities play a major role in customer online engagement. Questions 5-10 were designed to evaluate consumer attitudes about brand social media activities: whether they think it is important for brands to be active on social media in the first place, whether brands' social media has had a positive or negative impact on customers' perception of brands, if customers ever take advantage of the interactive quality of social media to communicate with brands, and what they expect.

4. Online advertising: Question 11 addresses this aspect. Since blatant online ads resemble traditional advertising in their nature, it was seen as enough to ask simply about customers' perception of them and whether the customer pays attention to them. 
5. A brand's mobile app or lack of it: The effectiveness of mobile apps was determined in this research by the aspects addressed in questions 12 and 13. It was important to find out whether customers utilize this option in the first place and their perceived effectiveness and benefit of using these apps if applicable.

6. A brand's communication with customers through email: E-mail correspondence is addressed in the final 3 questions (14-16). The questions address customers' usage of e-mail as a method of communication with brands, customers' evaluation of the level of responsiveness, customers' expectations when utilizing this aspect, how the engagement affects the customer's impression of a brand, and customers' opinion on e-mail as a brand communication tool in general.

(Ryan, 2014).

When analyzing the qualitative data obtained from the focus group, several approaches were used in obtaining results:

- First, was searching for important terms within the participants' answers. Key terms like "loyalty" or "awareness" and their derivatives were marked and counted, and the contexts in which they were used were analyzed. It was important to take note of such instances in which loyalty and awareness are directly addressed during the analysis, as they facilitate the understanding of the relation between loyalty, awareness and the online presence of a brand. Moreover, they show the customers' personal mindfulness of the existence of that relation.

- Next, remarks on the subject of interactivity, entertaining the customer, and overall engagement between brand and customer were tallied and analyzed. This was specifically put into focus when analyzing participants' answers on the questions related to social media and e-mail correspondence, as these are the aspects that include the highest level of personal engagement with customers.

- Third, each aspect of the six aspects selected for this research was analyzed individually. Customers' attitudes on each aspect were first simply checked under simple "favorable vs. unfavorable" basis. Negative attitudes (unfavorable) and positive attitudes (unfavorable) about every aspect were grouped together, and reasons provided by interviewees for having such attitudes about every aspect were listed and analyzed when possible. Any additional perspective provided by customers during the focus group about the aspects were also noted and mentioned in the results.

\section{RESUltS AND FindingS}

\subsection{Indicators of Brand Loyalty and Brand Awareness}

Since brand loyalty and brand awareness are the core concern of this research, it was important first to find all indicators of both within the participants' answers. To achieve that, all terms and phrases pertaining to brand loyalty and awareness mentioned by the participants were counted. The relevant terms found were not necessarily those that exactly match "loyal" and "aware", but were terms that basically signpost them. Such terms, when speaking about brand awareness, include terms like "discovering" brands, "finding out about" a brand, "learning" about new brands, for example. Indicators of loyalty were less straightforward, as a lot of factors hold the key to brand loyalty. Since trust is an important factor in maintaining customer relationships, terms pertaining to trust were counted as indicators of loyalty. Another factor leading to loyalty is repurchase, as repeated purchase is what paves the way to brand loyalty. Hence, terms or phrases that point out the intent to repurchase, such as "wanting to buy from the brand again" were counted as yet another indicator of loyalty. Other terms concerning loyalty that were found included mentions of "keeping customers" or "not losing customers", in addition to terms related to customer satisfaction.

From the focus group session, 19 out of 20 participants provided different indicators that relate to generating brand awareness in their answers; i.e. more than half of the participants have mentioned items relating to brand awareness. Most of these mentions pertaining to finding out or discovering new brands through the internet, as eight out of the 13 participants talked about these items.

Terms relating to brand loyalty were less obvious in their nature than those relating to brand awareness. Therefore, terms relating to repeated purchase, customer satisfaction, maintaining customer relations and of course direct mentions of loyalty were all included as indicators of loyalty. 
That is because even though a customer would not give outright mentions of loyalty, they could show signs of loyalty, or exhibit such factors that lead to loyalty as formerly mentioned. Based on that, the following table contains all indicators of loyalty found in the participants' answers:

16 out of 20 interviewees mentioned general indicators of brand loyalty, which is a significant number that accounts for $80 \%$ of all the participants. The highest count (five out of 15) was of terms relating to the intent of repurchase, or "wanting to buy from a brand again". The next highest count was of mentions of customer satisfaction (four out of 15). Both repeated purchase and customer satisfaction are closely related factors of building brand loyalty. Loyalty in itself, however, wasn't directly mentioned except three times.

One of the most important features of online communication is how it facilitates the interaction between the brands and their customers or prospective customers. Participants have addressed the interactivity aspect of brand's online presences in the focus group, and their mentions of different interactivity features were highlighted. Such instances include mentions of providing entertainment, the sharing of content described by participants as interesting, the engagement of customers, direct communication with customers, and customer feedback.

When addressing social media in particular, only a few of the participants mentioned different facets of interactivity. Six out of 20 customers talked about actually interacting with the brand via social media, which is only $30 \%$ of all the participants. This could mean that either the consumers are not utilizing the interactivity of social media enough, or that brands are not opening the door for customer engagement as they should. Most mentions of interacting with brands took place when talking about brand e-mail correspondence. 18 out of 20 participants, that is $85 \%$ of all the participants, saw e-mails as a tool for brands to interact directly with customers, suggesting types of e-mails brands should send to their customers. However, the interactivity discussed here by participants was mostly limited to customer feedback, customer complaints, and customer inquiries, which basically makes e-mail correspondence play the equivalent role of a brand's call center but on the internet. Other types discussed were promotion e-mails and new about product releases. Only five out of the said 17 participants spoke about personalized e-mails, such as thank you e-mails sent to customers after purchase, custom birthday greeting e-mails, holiday well-wishing e-mails, and tailored suggestions based on each customer's purchasing history.

On the entertainment side of brands' online engagement, many of the participants discussed providing entertainment value and content deemed "interesting". 10 out of 20 participants mentioned how posting "interesting" content on social media can make brands more appealing to them. The most common terms used to describe such content was "eye-catching" (used 4 times), "appealing" (used twice), and "visually pleasing" (used twice). As is evident, all of the 10 participants who talked about the content deemed "interesting" were addressing visual content only. No participant addressed any tangible entertainment value that could be provided by brands, but instead what was addressed here was simply aesthetics. Entertainment was also touched on when discussing online advertising, where four of the 20 (20\% of the total) participants added how entertaining advertisements can appeal to them. Such entertaining advertisements were described using terms such as "clever" (mentioned twice), "creative" (mentioned once), and "tasteful" (mentioned once).

\subsection{Analysis of the Different Aspects of a Brand's Online Presence}

When generally asked about the importance of a brand being active on the internet, there was a consensus amongst all participants that it was important. As 19 of the 20 participants said they either found it to be "important" or "very important. Only one participant said he does not find the internet to be that important to a brand, as he believes that traditional advertising does the job of promoting a brand well. The variation, however, was in the reasons given for why it is important.

The first question addressing the aspect of search engine results was whether customers ever found out about a brand through online searches. That is, if a customer's first contact with a brand happened through search results. 10 out of the 20 participants said that they have, indeed, discovered certain brands through search engines. One of the participants said she found a brand through a search engine advertisement, six participants said they found these brands when searching for other brands on a popular search engine, and three participants said they found the brands when searching for certain 
product categories. This means that half of all the participants became first aware of various brands through search engines alone.

18 out of the 20 participants said that they do look up brands they learned about on search engines in order to learn more about them. The participants had different views on what they would hope to find when searching for a brand on a search engine. The biggest number of participants, eight out of 18 , said they hoped to find a brand's website. Six out of the 18 said that they look for reviews about the brand. Four of them said that they look for product prices, and also four of them said they look for information about a brand's history or an overview of the brand. Three participants said they hoped to find store locations, three looked for product specifications, and another three hoped to find brands' social media pages. Only two participants said they looked for information about product availability. One participant mentioned wanting to know more about a brand's corporate social responsibility (CSR) activities, one participant said she sought to find a brand's online store, and one customer said she looks for pictures of the products.

The follow up question was on the participants' thoughts when they are unable to find a brand's website or any of its social media through online searches. 16 of the 20 participants revealed that such occurrence would hold a negative connotation to them. The four other participants were split between the two who previously mentioned that they do not use search engines to look up brands in the first place, and two others who said that it wouldn't mean much to them or that they wouldn't think anything based on it. The 16 participants who saw the lack of search engine results about a brand in a negative light described in different ways what it would make them think of the brand itself. Five of the 16 participants said that it indicated that the brand was an obscure or unpopular brand, while also five of the 16 said that it made them lose interest in the brand. Three of the participants said that it made them think that the brand was not trustworthy/not to be trusted. Two of them said it meant the brand was not a good quality brand, and two said that it would make them think that the brand is one that does not care for its customers. 1 customer described such a brand as "lame" or an uncool brand, one said that it indicated that the brand was "cheap" or not prestigious, and one said that it would make them think the brand was not even a real or legitimate brand.

The other question asked to the participants what they think an ideal brand website should look like or include in their opinion. Participants provided various answers. However, as with all the previous questions, there were many common threads that allowed to group the data into categories. The categories used here are basically all items mentioned by participants in their description of what ideal brand websites should include, with how often each item was mentioned by participants. The results are summarized in the following graph:

The highest demand from participants was for websites to contain product catalogues that include prices, emphasized by seven of the 20 participants. The next top three items, iterated by 6 participants each, were for photo galleries that contain pictures of the products, information about a brand's history or background, and information about store or outlet locations. Other significant items were including a brand's contact information on its website, having the website's design be simple or minimalistic in its nature, and incorporating an online store with shipping options, each stated by 4 participants. Offering special deals or discounts and offers on the brands website, and including a general information page about the brand were each stated by 3 participants. 2 participants said the website should have a distinctive design that goes along with the brand's overall them, and 2 participants added that they would like the website to have news about a brand's latest releases or launches as well as future ones. Items listed by only one participant each were: including product reviews by customers, having a feedback or rating page for customers to address their comments to the brand, and to have the website be available in multiple languages.

\subsection{Brand Social Media Activities}

Previous research has revealed how big a role social media plays in online marketing and customer engagement. Because of that, social media was put under special focus during the focus group, and different facets of brands' social media activities were addressed through an array of six questions. First, participants were asked if they found it was important for brands to be active on social media, and what the reason behind their opinion on that matter was.

Seven of the participants saw the value of social media in how it enables brands to reach new customers. Three of the participants said that it enhances a brand's image. Two of them said that it 
enhances the image by making the brand look more up to date with modern technology, while the remaining one participants said "it gives the impression that the brand cares about its customers...by trying to communicate more with them." Three participants said that it's simply important because social media is basically a free advertising medium for the brand. Two customers said it was a good way of getting feedback from the brand's customers, two saw it as an efficient way to keep customers updated with the brand's latest news, and lastly, two participants said it was a good way of building a closer relationship with the brand's customers.

Another 5 participants who did not think being active on social media is important to a brand also cited different reasons. The participants stated that they do not see social media as a vital medium for brands to use, but that it is essentially just a positive bonus for brands to be active on social media. One of the participants said that "if a brand is already well known, it does not need to use social media" and "I saw social media as a negative influence more than anything", stating that because "people abuse social media nowadays", it would only result in unnecessary clutter without any real benefit to the brand.

Next, the participants were asked participants if a brand's social media page ever enhanced their perception of a brand in a positive way and the answers obtained are as follows:

- "Clear photographs that are professionally captured with great resolution".

- "Demonstrating the product in a visually pleasing way".

- "Showing different sides and features of the products with creative photography".

- "Displaying their products in a unique and beautiful way."

- "Showing us their products in a way that makes it look useful and appealing to the customer".

As high quality showcasing was the leading item in inspiring positive perception of brands on social media, here, poor quality showcasing was the leading item in causing participants to have a negative perception of a band on social media, cited by three participants. Some of the answers obtained were:

- Being inactive on the page. The participants said that seeing that a brand's page was not regularly updated or hadn't been updated in a long time made them lose interest in the brand.

- Expressing controversial opinions on the page. Two interviewees said that they had seen brands post certain opinions they found controversial/disagreeable, and that that had made them dislike the brand.

- Seeing negative customer reviews on the page. Participants said that seeing negative comments or reviews from customers on the brand's page had given them a negative impression of the brand.

- Not responding to customers. Participants said that when they saw brands not actively communicating with customers or responding to their comments on the page, they got the impression that the brand does not care for its customers.

\section{DisCUSSION}

The results acquired from the focus group greatly disagree with the model chosen by the researcher as the one most ideal for online communication, which is the two-way symmetrical communication model. Even though social media allows for heavy exchange between brand and customer, and community engagement had proven to be effective in generating both brand awareness and loyalty in customers on several occasions (De Vries \& Carlson, 2014) (Hutter, Hautz, Dennhardt, \& Füller, 2013) (Kim \& Ko, 2012), that was not the case with the results obtained in this research. Only six of the 20 research participants recalled ever trying to communicate with brands through social media, which account for only $30 \%$ of the participants. Even when it came to e-mail correspondence, a mere seven out of the 20 participants, which is only $35 \%$ of the participants, said they had used e-mails to communicate with brands. This contradicts the two-way symmetrical communication model, in which both brand and customer would be engaging in back to back interaction where both of them have an equal amount of say. Additionally, participants revealed that the kind of interaction they had with brands were only for providing feedback, complaints or for inquiries, which makes the communication process between customer and brand in the UAE seem to follow the two-way 
asymmetrical model more than any other. The difference between the two-way symmetrical model and the two-way asymmetrical model is that under the two-way asymmetrical model, one side sends more messages and has more say while the other merely acts as a receiver who provides occasional feedback to the main sender's messages (Lattimore, Baskin, Heiman, \& Toth, 2011); and that is the closest model to what was demonstrated by the participants in the research. Possible explanations as to why interactivity between brands and customers in the UAE could be that:

1) Customers are not knowledgeable in utilizing the internet as a communication tool, or do not realize the effectiveness of the internet in communicating with brands.

2) Customers doubt the responsiveness of brands, or don't see that brands will be appropriately responsive to them. They could think that perhaps their messages will be neglected or ridiculed by the people behind a brand's page.

3) Brands have failed to utilize online communication in engaging their customers. It could be possible that brands in the UAE have not created space for dialogue with their customers, or have not made that space welcoming and engaging enough to bring the customers closer to them.

The participants demonstrated the internet's ability in generating the first step in the diffusion theory, which is awareness, when 10 of the 20 participants revealed that they have become aware of certain brands for the first time through the internet. In fact, 19 of the 20 participants mentioned indicators of awareness on different occasions throughout the focus group session. Seven of these participants were pointing out how they believed that social media could help brands reach new customers. The second step, interest, was also demonstrated by 10 of the 20 participants. These participants said that they would find a brand more appealing if the brand posts more content that they deem "interesting". However, the description of such content by the participants was limited to items that have mere visual appeal, without the mention of any more elaborate entertainment value. This could either mean that UAE audiences are not aware of the entertainment value that could be provided by brands through the internet, or that they have not been exposed to such value by the brands within UAE and therefore do not consider it as a possibility. However, if visuals are indeed enough to capture consumers' interest, that one makes it easier for UAE brands to bypass the second stage of the customer's appraisal under the diffusion theory. A lot of the participants mentioned the importance of brands asking for feedback from customers on several occasions, and six of the 18 participants who said they look up brands on search engines said that they look for reviews of the brand by other customers. That means that evaluation, the third step in the diffusion theory, partially takes place on the internet in UAE, as customers use other customers' opinions to verify their interest in brands.

The results can most be validated by the uses and gratification theory. All participant displayed a high level of mindfulness in their utilization of different aspects of brands' online presence. For every choice participants made, whether it was to utilize a particular medium or to avoid it, participants displayed conviction in their choice and were always able to provide one or more reasons for making such a choice. This mindfulness was most displayed by the participants when asked about online advertisements, where 12 of the participants revealed that they did not pay attention to online advertising, and two of the three participants who said they conditionally pay attention to these adds said they only pay attention if they are already interested in the brand. Hence, consumers on the internet do not just take in media messages, and simply sending out a message does not do the trick. In order to get a customer's attention, brands have to study what makes consumers make the choice between accepting and discarding the messages they see online.

\section{Conclusion}

The purpose of this study was to examine the effectiveness of a brand's online presence as a marketing tool, specifically in enforcing brand awareness and brand loyalty. The study focused on UAE millennials, and 20 millennials were chosen as participants in the focus group to gain their detailed insights on the subject. Previous research emphasized the effectiveness of the internet in generating brand awareness and reinforcing brand loyalty through capturing consumers' interest and creating ground for engagement with the brand's customers. However, the results obtained from the focus group revealed the lack of engagement between brands and customers in the UAE, as most participants denied using different online communication tools such as social media or e-mails to communicate with bands in the first place. And the only kind of communication exhibited among the few participants who did use the internet to communicate with brands was a customer service type of 
interaction; i.e. only communicating when having complaints, inquiries or feedback. Participants also did not mention getting any true entertainment value from brands' online presence, and the type of content they described as "interesting" was limited to mere visuals. Results point towards the importance of brands working on their online presence in the UAE, and making the best use of the online tools at hand. Community engagement is the key to improving that presence, and brands need to introduce that to customers by capturing their interest and winning their interest by providing them with tangible entertainment value as well as service value.

\section{REFERENCES}

Aaker, D. A. (2009). Managing Brand Equity. New York: Simon and Schuster.

Al-Jenaibi, B. N. (2011). Use of Social Media in the United Arab Emirates: An Initial Study. Global Media Journal - Arabian Edition, 1(2), 3-27.

Alrubaiee, L., \& Al-Nazer, N. (2010, May). Investigate the Impact of Relationship Marketing Orientation on. International Journal of Marketing Studies, 2(1), 155-174.

Close-Up Media Inc. (2014, June 16). Marketing to Millennials: Millennial Shoppers Trust Social Media More but Branch Out Beyond Facebook. Retrieved from ProQuest: http://adezproxy.adu.ac.ae/docview/1535585455?accountid=26149

Darby, R., Jones, J., \& Al-Madani, G. (2003). E-commerce marketing: Fad or fiction? Management competency in mastering emerging technology. An international case analysis in the UAE. Logistics Information Management, 16(2), 106-113.

De Vries, N. J., \& Carlson, J. (2014, August). Examining the drivers and brand performance implications of customer engagement with brands in the social media environment. Journal of Brand Management, 21(6), 495-515.

Dhaheri, E. A. (2015, January 3). UAE's new entrepreneurs turn to social media to pursue dreams. Retrieved from The National: http://www.thenational.ae/uae/uaes-new-entrepreneurs-turn-tosocial-media-to-pursue-dreams

Emirates 24/7 Staff. (2015, October 2). What is the most effective form of advertising in UAE? Retrieved from Emirates 24|7: http://www.emirates247.com/news/emirates/what-is-the-mosteffective-form-of-advertising-in-uae-2015-10-02-1.605339

Frady, D. (2011). Millennials' personal connection with brands via social media tools. Retrieved from ProQuest: http://adezproxy.adu.ac.ae/docview/1010409431 ?accountid=26149

Galvez, E. R. (2014, April 23). Increasing Brand Awareness in the Digital World: A Stakeholder Analysis. Retrieved from Student Theses @CBS: http://studenttheses.cbs.dk/handle/10417/4378

Gokulan, D. (2015, June 13). GCC women entrepreneurs find success on social media platforms . Retrieved from Khaleej Times: http://khaleejtimes.com/nation/general/gcc-womenentrepreneurs-find-success-on-social-media-platforms

Green, R. K. (2013, June 25). 7 Highly-Effective Ways to Maximize Your Online Brand Presence |R. Kay Green. Retrieved from Huffington Post: http://www.huffingtonpost.com/r-kay-green/onlinebrand-presence_b_3140951.html

Gulf News Staff Report. (2015, July 7). UAE consumers more active than global average on social media platforms. Retrieved from GulfNews.com: http://gulfnews.com/ business/sectors/media/ uae-consumers-more-active-than-global-average-on-social-media-platforms-1.1546594

Haque, A., Momen, A., Sultana, S., \& Yasmin, F. (2013, April). Online Brand Awareness: Determining the Relative Importance of Facebook and Other Strategies among the Malaysian Consumers. Information Management and Business Review, 168-174.

Hutter, K., Hautz, J., Dennhardt, S., \& Füller, J. (2013). The impact of user interactions in social media on brand awareness and purchase intention: the case of MINI on Facebook. The Journal of Product and Brand Management, 342-351.

Kim, A. J., \& Ko, E. (2012). Do social media marketing activities enhance customer equity? An empirical study of. Journal of Business Research, 1480-1486.

Koshy, S. (2013). Factors that affect the use of Facebook and Twitter as marketing tools in the UAE. Retrieved from Research Online - University of Wollongong: http://ro.uow.edu.au/ dubaipapers/ $489 /$ 
Lam, B., \& Verma, K. (2014, June). New Research Shows Search Ads Drive Brand Awareness . Retrieved from Think With Google: https://www.thinkwithgoogle.com/articles/search-ads-drivebrand-awareness.html

Lattimore, D., Baskin, O., Heiman, S., \& Toth, E. (2011). A Theoretical Basis for Public Relations. In D. Littmore, O. Baskin, S. Heiman, \& E. Toth, Public Relations: The Profession and the Practice (pp. 50-68). McGraw-Hill Education.

Maharaj, A. (2008, December 1). Awareness, perceptions and effects of customer loyalty programmes within the retail sector of the Durban Metropolitan area. Retrieved from University of South Africa: http://hdl.handle.net/10500/3127

Mouakket, S. (2009). Investigating the Factors Influencing Customers' Adoption of Online Banking in the United Arab Emirates. Journal of International Technology and Information Management, 18(3/4), 361-II.

Ryan, D. (2014). Understanding Digital Marketing: Marketing Strategies for Engaging the Digital Generation. Philadelphia: Kogan Page Limited.

Sabeeh, R. (2015, December 5). E-commerce in UAE forecasted to reach $\$ 10$ billion . Retrieved from Khaleej Times: http://www.khaleejtimes.com/business/economy/e-commerce-in-uae-forecastedto-reach-10-billion

Shabeeh, R. (2015, December 3). UAE's power of mobile apps . Retrieved from Khaleej Times: http://www.khaleejtimes.com/business/technology/uaes-power-of-mobile-apps

Zheng, X., Cheung, C. M., Lee, M. K., \& Liang, L. (2015). Building brand loyalty through user engagement in online brand communities in social networking sites. Information Technology \& People, 28(1), 90-106. 